\title{
Epstein-Barr virus and cryptogenic fibrosing alveolitis
}

The Epstein-Barr virus (EBV) is an ubiquitous infectious agent which causes seroconversion with measurable antibody levels in approximately $90 \%$ of young children in tropical regions and $30-40 \%$ of children from developed countries in the Northern hemsiphere. ${ }^{1}$ It is a member of the herpes virus family and has a double stranded DNA genome of 172000 base pairs that is divided into five unique regions with four internal and two terminal repeat domains. ${ }^{2}$ This genome exists in a linear form during a replicative infection where there is assembly of complete viruses, and in a circular or episomal form during latent infection where the cell is transformed without viral replication. ${ }^{2}$ The virus gains entry into cells using the CD21 molecule as a cell surface receptor. ${ }^{3}$ This molecule is also the receptor for the $\mathrm{C} 3 \mathrm{~d}$ component of complement, and cells that are ordinarily not permissive for EBV infection can be converted to permissive cells by transfecting them with the CD21 gene. ${ }^{2}$ In terminally differentiated cells, such as those found in parotid gland epithelium, EBV infection results in viral replication, shedding of viruses from the cell surface, and cell lysis. However, in less well differentiated basal epithelial cells and $\beta$ lymphocytes, infection results in the organisation of the viral genome into a circular extrachromosomal episome in the cell nucleus with expression of only about 10 of the approximately 80 genes encoded by the virus. ${ }^{3}$ Just how the expression of this limited number of viral genes is able to transform the cell is of great interest.

The widespread nature of EBV infection suggests that many normal adults must harbour EBV infected $\beta$ lymphocytes that have the potential for unlimited growth. ${ }^{12}$ The fact that lymphoproliferative disorders involving EBV infected cells are rare indicates that the proliferation of these cells is successfully restrained by the host immune response. The hypothesis that EBV infection was important in any form of chronic lung disease was first put forward by Liebow and Carrington ${ }^{4}$ who speculated that the lymphocyte proliferation which they described in lymphocytic interstitial pneumonia might be due to EBV infection. In later studies conducted on some of the same cases described by Liebow and Carrington, Barbera and colleagues ${ }^{5}$ were able to show that the internal repeat DNA sequence of the EBV was present in the type II epithelial cells of patients with lymphocytic interstitial pneumonia. However, they failed to demonstrate convincingly this EBV DNA sequence in the $\beta$ lymphocytes present in the lesions, presumably because the DNA copy numbers were too low.

In this issue of Thorax, Egan and associates ${ }^{6}$ provide $^{-}$ immunocytochemical evidence that the type II cells proliferating in lesions of cryptogenic fibrosing alveolitis contain proteins coded by two of the EBV genes that are expressed during a replicative EBV infection. This important observation shows that the type II cells present in the lesions have harboured a replicative EBV infection at some time, but does not prove that the virus was replicating at the time of the biopsy, nor does it establish a causal link between replicating EBV and fibrosing alveolitis. Others have suggested that the lung is a reservoir for $\mathrm{EBV},{ }^{7}$ and the present study provides new information suggesting that replication does occur in the type II cells, particularly in patients with cryptogenic fibrosing alveolitis. Comparison of their finding with those of Barbera et al, who showed that the internal repeat sequence of EBV DNA was present in the type II cells from patients with lymphocytic interstitial pneumonia but not those with fibrosing alveolitis whom they used as controls, suggests a discrepancy between the two studies that needs to be resolved. Experiments that examine lung tissue for viral DNA, RNA, and proteins will be needed to clarify why the EBV replicative proteins might be present when the internal repeat DNA is not.

The observations reported by Egan et al are also of interest with respect to recent reports linking EBV infections to the development of benign and malignant smooth muscle tumours in children with AIDS $^{8}$ and in patients immunosuppressed for transplantation. ${ }^{9}$ If EBV infection can transform smooth muscle cells and allow them to proliferate, it is also possible that it might transform fibroblasts and produce the connective tissue changes that characterise fibrosing alveolitis. The virus presumably infects epithelial cells first producing replicating infection, and the lymphocytes become infected as they circulate through the epithelium. Just how an infected epithelial cell or a lymphocyte might then infect and transform a smooth muscle cell ${ }^{89}$ or a fibroblast remains to be determined. In spite of these difficulties, the observation by Egan et al that the type II cell is infected by replicating EBV in patients with cytogenic fibrosing alveolitis provides an important new lead in the investigation of the process that deserves to be carefully followed up.

Director of Pulmonary Research Laboratory,

JAMES C HOGG

St Paul's Hospital,

1081 Burrard Street,

Vancouver,

British Columbia,

Canada V6Z 1 Y6

1 Miller G. Epstein-Barr virus. In: Fields BN, ed. Virology. New York: Raven Press, 1985:563-89.

2 Strauss SE, Cohen JI, Tosato G, Meyer J. Epstein-Barr virus infections: biology, pathogenesis and management. Ann Intern Med 1993;118:45-58.

biology, pathogenesis and management. Ann Intern Med 1993;118:45-58.
Fingeroth JD, Weiss JJ, Tedder TF, Strominger JL, Biro PA, Fearon DT. Epstein-Barr virus receptor of human $\beta$ lymphocytes in the $C 3 \mathrm{~d}$ receptor Proc Natl Acad Sci USA 1984;81:4510-4.

4 Liebow AA, Carrington CD. Diffuse pulmonary lymphoreticular infiltrations associated with dysoproteinemia. Med Clin North Am 1973;57:809-43.

5 Barbera JA, Hayashi S, Hegele RG, Hogg JC. Detection of Epstein-Barr virus in lymphocytic interstitial pneumonia by in situ hybridization. $A m$ Rev Respir Dis 1992;145:940-6.

6 Egan JJ, Stewart JP, Hasleton PS, Arrand JR, Carroll KB, Woodcock AA. Epstein-Barr virus replication within pulmonary epithelial cells in cryptogenic fibrosing alveolitis. Thorax 1995;50:1234-9.

7 Lung ML, Lam WK, So SY, Lam WP, Chan KH, Ng MH. Evidence that respiratory tract is major reservoir for Epstein-Barr virus. Lancet 1985; i: 889-92.

8 McClain KL, Leach CT, Jenson HB, Joshi VV, Pollock BH, Parmley RT, et al. Association of Epstein-Barr virus with leiomyosarcoma in young people with AIDS. $N$ Eng $\mathcal{F}$ Med 1995;332:12-8.

9 Lee ES, Licker J, Nalesnik M, Reyes J, Jaffe R, Alashari M, et al. The association of Epstein-Barr virus with smooth-muscle tumour occurring after organ transplantation. $N$ Engl $¥$ Med 1995;332:19-25. 